1. Associate Prof. Department of Pediatrics IMC Faisalabad.

2. Senior Registrar

Allied Hospital Faisalabad

3. Assistant Prof.

Department of Pediatrics

DHQ Hospital Faisalabad.

4. Prof. Department of Pediatrics

IMC Faisalabad

5. Assistant Prof.

Department of Pediatrics

IMC Faisalabad

Correspondence Address:

Dr. Sadida Aamir

Associate Professor

Department of Paediatrics

Independent Medical College,

Faisalabad.

Article received on: 04/09/2015

Accepted for publication:

14/11/2015

Received after proof reading:

00/00/0000

\section{PHOTOTHERAPY; \\ FREQUENCY OF HYPOCALCEMIA IN NEONATES UNDERGOING IN TERTIARY CARE HOSPITAL IN FAISALABAD}

Dr. Sadida Bahawal', Dr. Umm-Ul- Baneen Naqvi ${ }^{2}$, Dr. Mehboob Alam Siddiqui ${ }^{3}$, Dr.Shakil Ahmad ${ }^{4}$, Dr.Imran Sarwar ${ }^{5}$

ABSTARCT... Hyperbilirubinemia is the most common abnormal physical finding in first few weeks of lif and its most common management is phototherapy. Amongst other common complications a less known complication of phototherapy is hypocalcemia. Objectives: To study the incidence of phototherapy induced hypocalcemia in neonates and to have a comparison between preterm and term neonates. Study design: Descriptive cross-sectional study. Setting: Paediatric Unit II DHQ Hospital Faisalabad, which is a tertiary care centre for all kind of patients. Duration of study with dates: Six months from 1-11-2012 to 30-04-2013. Methods: 196 neonates with hyperbilirubinemia full term / preterm neonates admitted in pediatric DHQ hospital faislabad were selected. Inclusion criteria. 1) Hyperbilirubinemia. 2) No hypocalcemia on admission. 3) Received phototherapy for hyperbilirubinemia. Serum Calcium levels were measured in all neonates before and 48 hours after receiving phototherapy. Incidence of hypocalcemia among all neonates was calculated as an absolute percentage and the sample population was also divided into preterm / full term neonates to evaluate the incidence of hypocalcemia in these two groups individually. RESULTS: Mean serum calcium in neonates was $7.5+-1.5 \mathrm{mg} / \mathrm{dl} .16 .84 \%$ of neonates were found to have calcium level below the cut off value. 33 out of 196 developed hypocalcemia after phototherapy and out of these $54 \%$ were preterm and $45 \%$ were term neonates $<$ P-value $(0.01)>$. Conclusion: Phototherapy induces hypocalcemia in neonates more so in preterm neonates. Impact: Consideration for additional calcium supplementation should be undertaken in all neonates undergoing phototherapy and further randomized trials need to be done with these concerns.

Key words: neonate. Hyperbilirubinemia / hypocalcemia / phototherapy.

Article Citation: Bahawal S, Naqvi UB, Siddique MA, Ahmad S, Sawrar I. Phototherapy; frequency of hypocalcemia in neonates undergoing in tertiary care hospital in Faisalabad. Professional Med J 2015;22(12):1541-1545. DOI: 10.17957/ TPMJ/15.3082

\section{INTRODUCTION}

Hypocalcemia is a rare but potential side effect of Phototherapy. ${ }^{1,2}$ Other Potential risks of phototherapy are minimum in full term but may be significant for extremely low birth weight infants. These include insensible water loss, loose stools, retinal damage, erythematous macular rash, overheating, hypothermia, bronze baby syndrome..$^{1,2,3}$ Fifteen percent of neonates undergoing phototherapy develop hypocalcemia. ${ }^{5}$ It has been suggested that phototherapy reduces melatonin secretion which not only regulates sleep cycle but also decreases glucocorticoid secretion leading to an increase in bone calcium uptake resulting in hypocalcemia. ${ }^{5}$ Normal range of serum calcium in neonates is between $9-11.5 \mathrm{mg} / \mathrm{dl}$ and symptoms appear below $8 \mathrm{mg} / \mathrm{dl}$ in term and $7 \mathrm{mg} / \mathrm{dl}$ in pre term neonates. ${ }^{6,7,11}$ Symptoms of hypocalcemia include neuromuscular irritability, myclonic jerks, jitteriness, exaggerated startle, seizures, recurrent chest infections, cyanosis, tachypnoea and larygospasm..$^{7,11}$

Phototherapy is the first treatment of choice for jaundiced neonates. ${ }^{8}$ Jaundice is observed during the $1^{\text {st }}$ week of life in approximately $60 \%$ of term and $80 \%$ of preterm infants. ${ }^{3,4}$ Hyperbilirubinemia is asymptomatic but begins to cause jaundice at $>4$ to $5 \mathrm{mg} / \mathrm{dll}^{4}{ }^{4}$ With increasing bilirubin levels, visible jaundice advances in head to foot directions. ${ }^{8}$ Elevated serum bilirubin levels in neonates can be damaging to the developing neural system if not adequately monitored and 
treated, resulting in kernicterus. ${ }^{1,9,10}$ Approximately upto $10 \%$ of these jaundiced neonates have significant hyperbilirubinemia mandating the use of phototherapy. ${ }^{8}$ It comprises of lamps with output predominantly in the blue region of spectrum (460 - 490nm) being most effective. ${ }^{3,4,8}$ Phototherapy has decreased the need for exchange transfusion in term and per term infants with hemolytic and non hemolytic jaundice. ${ }^{4}$

A study conducted on 82 cases of neonatal hyperbilirubinemia undergoing phototherapy revealed that incidence of hypocalcemia in neonates was $15 \%$ after phototherapy and the covering of neonate's head and occipital area during phototherapy decreases phototherapy induce hypocalcemia. ${ }^{5}$ My study will generate local statistics which may give rise to studies that would help us to lower the risk of hypocalcemia related adverse effects.

\section{Objectives}

1. To determine incidence of hypocalcaemia in neonates undergoing phototherapy.

\section{METHODOLOGY}

This descriptive cross sectional study was conducted in paediatric unit II DHQ Hospital Faisalabad, which is a tertiary care center for all kinds of patients. The study was conducted from November 2012 to April 2013. All neonates (from birth to 28 days of life) ${ }^{4}$ with hyperbilirubinemia, which is defined as elevation of the bilirubin levels in the blood of newborn which result in yellowish staining of the skin and sclera by pigments of bile and those having bilirubin below the exchange transfusion range which is taken as bilirubin level less than $20 \mathrm{mg} / \mathrm{dl}$ depending upon the age and gestation of the neonates, were included in the study. Neonates having documented hypocalemia (serum calcium less than $7 \mathrm{mg} / \mathrm{dl})^{4}$ prior to the start of phototherapy, those receiving calcium supplementation or with bilirubin levels in range of exchange transfusion were excluded from the study.

196 neonates admitted in Pediatrics ward DHQ Hospital, Faisalabad through outpatient department, emergency department or via consulting clinics with hyperbilirubinemia were selected after explaining the purposes, procedure, risk (hypocalcemia) and benefits (avoidance of kernicteus) of the study. All ethical issues were addressed and informed consent from the parents/ guardians were taken. A detailed history and clinical examination was performed on every patient. Hyperbilirubinemia \& hypocalcemia was documented by blood samples sent the Lab and reported by pathologist. Serum calcium was monitored on arrival and 48 hours of phototherapy and 24 hours after discontinuation of phototherapy. The entire data was carefully collected through specially designed Proforma containing bio data, gestational age and investigations.

Finally the data was analyzed. For continuous variables (serum bilirubin, serum calicium) mean \& standard deviation were calculated. For categorical variables (sex, gestational age and hypocalcemia) frequency and percentages were reported. SPSS statistical software version 10 was used for the data analysis.

\section{RESULTS}

196 neonates with hyperbilirubinemia were studied. Mean serum calcium in neonates was $7.5+-1.5 \mathrm{mg} / \mathrm{dl}$. $16.84 \%$ of neonates were found to have calcium level below the cut off value. 33 out of 196 developed hypocalcemia after phototherapy and out of these 54\% were preterm and $45 \%$ were term neonates $\langle$ P-value $(0.01)>$. The distribution of hypocalcemia among male and female was almost the same, hence there was no gender difference regarding hypocalcemia in the neonates.

\begin{tabular}{|c|c|c|}
\hline Gestational Age & Number & Percentage \\
\hline Term & 134 & $68.37 \%$ \\
\hline Preterm & 62 & $31.63 \%$ \\
\hline Total & 196 & $100 \%$ \\
\hline \multicolumn{2}{|c|}{ Distribution of cases by age. } \\
\hline Sex & Number & Percentage \\
\hline Male & 89 & $45.40 \%$ \\
\hline Female & 107 & $54.60 \%$ \\
\hline Total & 196 & $100 \%$ \\
\hline \multicolumn{2}{|c|}{ Distribution of cases by sex. } \\
\hline
\end{tabular}




\begin{tabular}{|c|c|c|c|}
\hline & \multicolumn{2}{|c|}{ Hypocolumia } & \\
\cline { 2 - 3 } & NO & Yes & Total \\
\hline $\begin{array}{c}\text { Gestational Term age } \\
\text { Pre Term }\end{array}$ & $55 \%$ & $45 \%$ & $100 \%$ \\
\hline Gestational Aga / Hypocalcemia Crosstabulations \\
\hline \multicolumn{2}{|c|}{ Percentage } \\
\hline
\end{tabular}

\begin{tabular}{|c|c|c|c|}
\hline \begin{tabular}{|c|} 
Gestational age* \\
hypocalcemia crosstabulation \\
Count
\end{tabular} \\
\hline & \multicolumn{3}{|c|}{ Hypocalcemia } \\
\hline No & Yes & Total \\
\hline Age preterm & 121 & 15 & 136 \\
Total & 42 & 18 & 60 \\
\hline Table-I. Cross tabulation between gestational age \\
\hline \multicolumn{3}{|c|}{ and hypocalcemia } \\
\hline
\end{tabular}
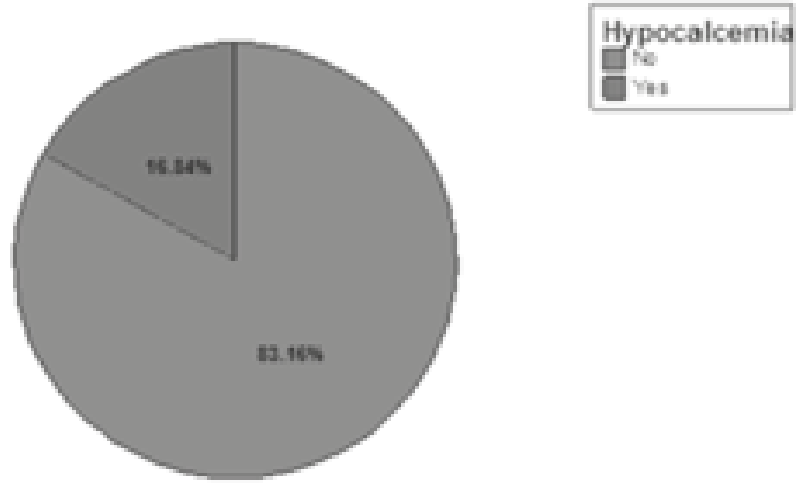

Figure-I. Distribution of neonates with and without hypocalcemia after receiving phototherapy.

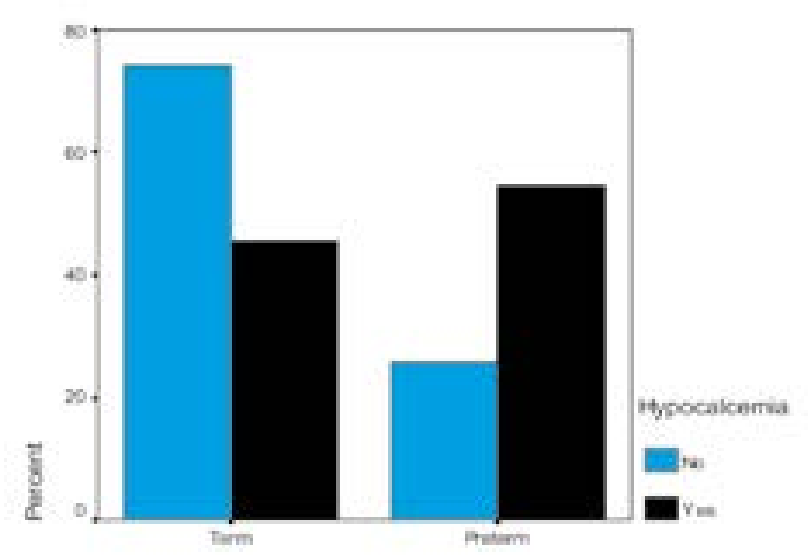

Gestational Age

Figure-2.

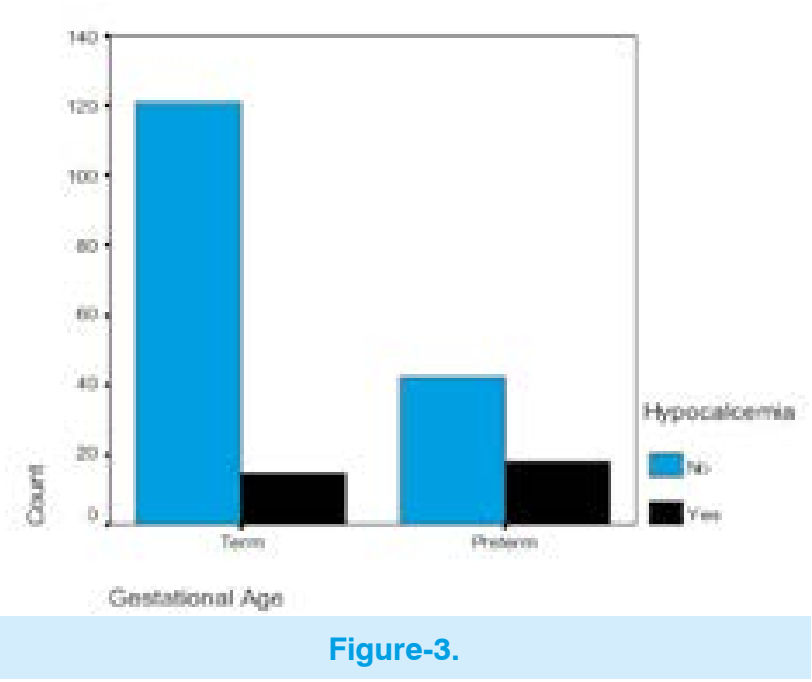

\section{DISCUSSION}

Phototherapy was discovered by Cremer at all in 1958 that light has ability to decrease Jaundice in neonates, Phototherapy is a relatively inexpensive and non invasive method of treating hyperbilirubinemia due to effective phototherapy number of exchange transfusions is markedly reduced in recent year.

Absorption of light by bilirubin results in formation of photo oxidation products which are excreted in urine.

Study in Pakistan shows that $10-30$ infants per 1,000 require photo therapy due to multiple causes prematurity, sepsis, Iso immune hemolytic disease, Asphyxia, Acidosis most important contraindication of photo therapy is porphyries.

Hypocalcaemia is a low level of calcium which occurs in new born due to infections, infants of diabetic mother, Asphyxia and prematurity.

Our study shows that incidence of hypocalcemia in neonates, receiving phototherapy for hyperbilirubinemia, is higher. A Prior study with a smaller sample size revealed a similar relationship. In which thirty neonates (16.4\%) developed hypocalcemia. ${ }^{14}$

Study done by Habib zadeh in Bangladesh shows significant differences between the prevalence of hypocalcemia during phototherapy in premature 
(40. 5\%) and full - term neonates (16\%) $(p=$ 0.019). ${ }^{15}$ This study reveals that calcium level return to normal on cessation of phototherapy. Our Study shows almost same percentages trends owing to larger sample size.

The increased incidence in preterm neonates can be explained by Infants born premature may have underdeveloped parathyroid glands. The hormone these glands produce regulates levels of calcium in the blood. Premature birth can cause hypocalcemia because underdeveloped parathyroid glands are unable to produce adequate amounts of parathyroid hormone to regulate infant blood calcium levels. ${ }^{16}$

Study by Hooman et. al evaluate the relationship of serum and urinary level of calcium in premature receiving phototherapy. This study results shows that hypocalciuria is a cause of hypocalcaemia.

Sarora done study in Nepal reports that hypocalcaemia frequently occurred after $48 \mathrm{hrs}$ of continues phototherapy in both term and preterm babies.

Study done by Bergstrom propose that newborn with jaundice exposed to fluorescent light shows fall in concentration of serum calcium, this hypocalcemia is due to increased calcium update by bone due to phototherapy.

Zahraa Ezzeldin hypothesized that phototherapy inhibit pineal secretion of melatonin which block cortisol effect on bone calcium and induce hypocalcemia. Phototherapy induced hypocalcemia can be prevented by covering head study shows that $9.7 \%$ with head cover shows hypocalcemia and 24.2 without head cover $p=0.031$.

In another study done in Tehran a significant fall in serum calcium level in preterms and term babies after phototherapy was observed. In preterm babies incidence of hypocalcemia was study $(50 \%)$ and in term babies hypocalcemia is $35 \%$. Preterm's, (63.6\%) had jitteriness and 3 (25.3\%) had irritability. In this study $40 \%$ had jitteriness and $(17.6 \%)$ was irritable in term babies. ${ }^{17}$ Further studies with these interventions can help in reasoning and management of such cases.

\section{CONCLUSION}

Phototherapy induces hypocalcemia in neonates more so in preterm neonates. Some small studies have revealed intervention strategies like covering the occiput, in lowering the level of hypocalcemia and its incidence. Futher control trails and intervention studies are needed to establish this data and initiate interventions like additional calcium supplements and covering of head with phototherapy treatment to decrease the incidence of hypocalcemia in neonates under this group.

This study will be helpful in demonstrating the disease burden and establishing the preventive strategies in our setup.

However like any good study, it has raised further question on the issues which should be addressed by larger study on effect of hypocalcemia caused by phototherapy.

\section{Copyright(C) 14 Nov, 2015.}

\section{REFERANCES}

1. Jangaard KA, Vincer MJ, Allen AC. A randomized trial of aggressive versus conservative phototherapy for hyperbilirubinemia in infants weighing less than $\mathbf{5 0 0}$ g: short and long term outcomes. Pediatr Child Health 2007; $12: 853-7$.

2. Houman N, Taheri DN, Samaei H, Arab M H AA. Blood level and urinary excretion of calcium in neonates with non physiological hyperbilirubinemia under phototherapy. J Iran Univ Med Sci Spring 2009; 16: 195-202.

3. Maisels MJ, Mc Donagh AF. Phototherapy for neonatal jaundice. N Engl J Med 2008 : 358:958:920-8.

4. Pizza AJ. Stoll BJ Jaundice and hyperbilirubinemia in the newborn. In: Kilegman RM, Behrman RE, Jenson HB, Stanton BF, Nelson textbook of pediatrics. Vol. 1. $8^{\text {th }}$ ed. Philedelphia: Saunders 2007: 671-809.

5. Ehsanipour F, Khosravi N. Jalali S. The effect of hat on phototherapy induced hypocalcemia in incteric newborn J Iran Univ Med Sci 2008; 15:25-9.

6. Nahid Q, Nejmadin M, Pasha M, Vahid SG, Sabah 
H. Vitamin D, Calcium and phosphorus status of pregnant women and their newborn in West Iran. Rawal Med J 2007: 32: 17 -20.

7. Khan HI, Abdullah A, Kazi MY, Afzal MF. Hypocalcemia and nutritional rickets in children common etiological factors. Ann Med Coll 2006; 12:29:32.

8. Mishra S, Agarwal R, Deorari AM king Edhood Med Coll AK, Paul VK. Jaundice in the newborn. Indian J Pediatr 2008: 75:157-63.

9. Watchko JF, Neonatal Hyperbilirubinemia what are the risks? N Engl J Med 2006; 354: 1947-9.

10. Bhutani VK, Johnson L. Prevention of severe neonatal hyperbilirubinemia in healthy infants of $\mathbf{3 5}$ or more weeks of gestation: implementation of a systems based approach J Pediatr 2007; 83: 289-93.

11. Jain A. Agarwal R, Deerari Ak, Paul VK. Hypocalcemia in the newborn. Indian J Pediatr 2008; 75:165-9.

12. Erlandsen MA, Hansen TWR. Treatment of Neonetal
Jaundice - more than phototherapy and exchange transfusion. Eastern J Med 2010; 15: 175 -85.

13. Mukherjee s, Ketz J. Bilirubin impaired conjugation. [on line] [cited 2010 january 3] available from: http:// emedecine.medscape.com / article / 171585-over view.

14. Kamamifar $\mathrm{H}$, Amir HGH, Pishva N. Prevalance of phototherapy induced hypocalcemia. Iran J Med Sci 2002; 27: 166 - 8.

15. Hakanson Do Berstrom WH. Phototherapy induced hypocolcemia in newborn rats: preveation by melatonin. Scie J 2007; 214: 807 - 9.

16. How does premature birth cause infant hypocalcemia. [online] [cited 2010 October 10] available from: www. sharecare.com /----/how. Premature - birth - cause hypocalcemia.

17. Tandon M, Nayer D, Ramchandran S, kapil U. phototherapy induced hypocalcemia. Indian J Pediatr 2006 ; 35: $566-7$.

\section{AUTHORSHIP AND CONTRIBUTION DECLARATION}

\begin{tabular}{|c|c|c|c|}
\hline Sr. \# & Author-s Full Name & Contribution to the paper & Author $=\mathbf{s}$ Signature \\
\hline 1 & Dr. Sadida Bahawal & $\begin{array}{l}\text { Paper weiting \& data } \\
\text { collection }\end{array}$ & sapule. \\
\hline 2 & Dr. Umm-ul-Baneen Naqbi & Data collection & \\
\hline 3 & Dr. Mehboob Alam Saddiqui & Analysis data collection & \\
\hline 4 & Dr. Shakil Ahmad & $\begin{array}{l}\text { Data collection \& } \\
\text { supervision }\end{array}$ & \\
\hline 5 & Dr. Imran Sarwar & Data collection & \\
\hline
\end{tabular}

